Sejarah, No. 26, Bil. 1, Jun 2017, hlm. 72-82

\title{
KEGIATAN PERNIAGAAN SUSU DI KUALA LUMPUR PADA AWAL ABAD KE-20
}

\author{
Shapiza Sharif \\ Arba'iyah Mohd Noor
}

\begin{abstract}
Kuala Lumpur became popular in 1880 since the British administration centre was located in the city thus replacing Klang as the capital city of Selangor. People saw the business potential of Kuala Lumpur when the city was later chosen as the capital of Federated Malay States in 1896. Hence, the city became the best business platform due to its high status. Even though milk industry was not as extravagant as mining industry and it was not the primary business in the economy of Kuala Lumpur, milk industry was significant in the aspect of food source and health benefit. Hence, the distribution process and marketing of fresh milk was strictly controlled according to its rules. This article will be discussing the development of milk industry in Kuala Lumpur in early 20 century and the factors that influenced the business during that time as well as how the milk business was carried out in Kuala Lumpur. The most data used in this article are primary sources and the scope of the discussion is narrowed to Kuala Lumpur in early 20 century.
\end{abstract}

\section{Pengenalan}

Langkah awal pihak British mencorakkan ekonomi ${ }^{1}$ Kuala Lumpur ${ }^{2}$ adalah dengan menjadikan Kuala Lumpur sebagai ibu kota Selangor menggantikan Klang dan pusat pentadbiran British pada tahun 1880. Kedua-dua status tersebut telah memberi kelebihan kepada Kuala Lumpur menjadi tumpuan kegiatan ${ }^{3}$ perlombongan bijih timah dan pelbagai kegiatan ekonomi pada ketika itu. Walaupun susu bukan kegiatan perniagaan yang besar di Kuala Lumpur, tetapi kegiatan perniagaan susu ${ }^{4}$ signifikan di Kuala Lumpur. Dalam kes Kuala Lumpur, kepentingan susu sebagai sumber pemakanan dan kesihatan penduduk pada ketika itu. Maka tidak hairanlah, proses pengeluaran susu dikawal dengan penuh peraturan dan proses pemasaran susu yang dikawal ketat membuktikan kegiatan perniagaan susu penting di Kuala Lumpur. Malah rangkaian kegiatan perniagaan susu di Kuala Lumpur merupakan salah satu kegiatan ekonomi yang dijalankan secara terancang di bandar Kuala Lumpur. ${ }^{5}$ Oleh itu, wajar susu diketengahkan sebagai salah satu kegiatan ekonomi di Kuala Lumpur. Maka artikel ini dapat memberi penjelasan terperinci bagaimana kegiatan perniagaan susu telah dijalankan di Kuala Lumpur pada awal abad ke-20.

\section{Faktor-faktor Perkembangan Kegiatan Perniagaan Susu di Kuala Lumpur}

Permintaan susu yang tinggi merupakan faktor dominan perkembangan kegiatan perniagaan susu di Kuala Lumpur. Pasaran susu yang luas dalam pemakanan dan kesihatan menjadikan kegiatan perniagaan susu begitu kompetetif di Kuala Lumpur. Dengan kata lain, penawaran susu di Kuala Lumpur untuk kegunaan rutin harian. Kekuatan kegiatan perniagaan susu di Kuala Lumpur kerana pasaran susu tidak terhad untuk kegunaan isi rumah sahaja malah peniaga-peniaga dalam bidang bakeri. Selain susu diminum langsung, kepentingan susu bagi peniaga-peniaga bakeri dijadikan salah satu bahan utama untuk membuat roti dan kek di Kuala Lumpur. ${ }^{6}$ Kepentingan 
susu dalam perniagaan bakeri dapat menjadi adunan pelengkap menaikkan aroma roti dan kek dan enak untuk dimakan.

Kepentingan susu untuk kesihatan kerana mengandungi pelbagai khasiat untuk merawat penyakit secara semula jadi. Dalam hal ini, susu bertindak menjadi antibodi dalam tubuh badan. Pada masa yang sama, susu mampu menjadi sistem imunisasi tambahan dan membantu sistem penghadaman. Meneliti faktor ini memberi kelebihan untuk perkembangan kegiatan perniagaan susu di Kuala Lumpur. Selain kandungan kalsium yang tinggi mengurangkan risiko osteoporosis, susu juga mengandungi sumber vitamin B1 dan berfungsi menjaga keseimbangan air dalam tubuh. Vitamin B1 dapat menyembuhkan penyakit beri-beri yang boleh mengancam nyawa. Memandangkan khasiat yang terkandung dalam susu dapat merawat penyakit secara semula jadi, maka banyak tender bekalan susu ke Hospital Kuala Lumpur. ${ }^{7}$

Pola peningkatan penduduk di Kuala Lumpur berterusan terutama pada awal abad ke-20. Pada tahun 1901 penduduk di bandar Kuala Lumpur sebanyak 32,381. Pada tahun 1911 populasi penduduk Kuala Lumpur telah mencecah sebanyak 46,718. Trend peningkatan penduduk di Kuala Lumpur berterusan iaitu mencatatkan sebanyak 80,424 pada tahun 1921. ${ }^{8}$ Kuala Lumpur boleh dikatakan bertuah kerana keadaan pertambahan penduduk secara mendadak dapat memberi ruang untuk memasarkan susu. Manifestasi positif daripada pertambahan jumlah penduduk ialah menjamin permintaan pasaran susu di Kuala Lumpur. Senario ini memberi petanda baik kepada semua pembekal dan peniaga susu di Kuala Lumpur.

Dengan adanya inovasi peralatan susu yang dibawa masuk ke Kuala Lumpur pada ketika itu, jelas menunjukkan kesungguhan pentadbiran British untuk menjayakan kegiatan perniagaan susu. Tegasnya, perniagaan susu di Kuala Lumpur pada masa itu telah bergerak ke hadapan dan tidak menggunakan kaedah primitif semasa proses pembungkusan. Buktinya, penggunaan Alpha Filter No. 3 dan Extra Filter Medium dapat membantu proses menyaring susu dengan lebih baik. Manakala itu, penggunaan Hot Water Mixer dapat memastikan susu dikacau dalam kuantiti yang banyak dan sekata. ${ }^{9}$ Usaha memaksimumkan kualiti susu dapat dilihat dengan pengenalan berus khusus. ${ }^{10}$ Walaupun teknologi ini dianggap mudah pada saat ini, namun teknologi peralatan ini dikira penemuan baharu yang menjadikan proses pembekalan susu cekap saat itu. Keadaan ini secara tidak langsung mengesahkan kepentingan kegiatan perniagaan susu apabila peralatan inovasi ini diimport ke Kuala Lumpur melalui Crown Agents. ${ }^{11}$ Ini bermakna perniagaan susu telah mula diusahakan secara komersial di Kuala Lumpur pada awal abad ke-20.

Kepentingan susu di Kuala Lumpur dapat dilihat daripada lambakan pelbagai jenama susu di pasaran Kuala Lumpur. Bayangkan terdapat susu yang popular pada masa kini telah ada di Kuala Lumpur pada awal dekad ke-20. Ini bermaksud perniagaan susu di Kuala Lumpur pada masa itu telah jauh ke hadapan. Misalnya, jenama Nestle's Milkmaid Sweetened Condensed, Borden's Eagle Sweetened Condensed, Nestle's Ideal Unsweetened Condensed, Borden's St. Charles Evaporated Cream, Borden's Peerless Evaporated Milk dan Nestle's Milkmaid Sterilised Natural dapat diperoleh di pasaran Kuala Lumpur. ${ }^{12}$ Penduduk juga boleh memperoleh susu berjenama Fussel's Green Butterfly Pure Cow's Milk, Fussel's White Butterfly Pure Cow's Milk, Condensed Milk, Unsweetened, Fussel's Golden Butterfly Pure Thick Rich Sterilized Cream di pasaran Kuala Lumpur. ${ }^{13}$ Pilihan jenama susu yang banyak ini telah menjadi kekuatan perkembangan kegiatan perniagaan susu di Kuala Lumpur. Dengan pelbagai jenama susu di Kuala Lumpur telah memberi penduduk lebih banyak pilihan ketika membeli susu. Pada masa yang sama, susu boleh dibeli mengikut keperluan mereka sekali gus membantu menggerakkan kegiatan perniagaan susu di Kuala Lumpur. 
Dengan pengeluaran notis arahan berkenaan susu menggambarkan keadaan penjualan susu dikawal ketat di Kuala Lumpur. Walau bagaimanapun peraturan-peraturan ketat ini tidak menghalang penawaran susu di Kuala Lumpur. Dari segi jangka panjang garis panduan ini memudahkan urusan pembekalan susu di Kuala Lumpur. Penyelarasan harga dan kualiti susu dalam notis arahan dapat memastikan hak pembeli-pembeli susu dilindungi. Pengeluaran notis arahan melindungi pembeli-pembeli susu agar tidak ditipu dari segi harga dan kualiti susu yang dijual di Kuala Lumpur. Keadaan ini terjadi kerana menerusi notis arahan semua peniaga susu di Kuala Lumpur perlu akur dengan kandungan maklumat terperinci mengenai susu untuk mengelak diri daripada didakwa. ${ }^{14}$

\section{Kegiatan Perniagaan Susu di Kuala Lumpur}

Langkah menggerakkan kegiatan perniagaan susu pada peringkat awal di Kuala Lumpur dengan memastikan penawaran susu dapat menampung kehendak pasaran. Kecenderungan untuk mengusahakan kegiatan perniagaan susu dapat dilihat daripada permohonan tanah seluas 25 ekar di Kuala Lumpur telah diterima oleh kerajaan. Tanah tersebut diusahakan sebagai kawasan penternakan lembu khusus untuk mendapatkan susu. Jika diamati pemberian tanah ini dapat meningkatkan pengeluaran susu sekali gus dapat menampung keperluan susu di sekitar Kuala Lumpur. ${ }^{15}$

Kepentingan susu untuk pemakanan dan kesihatan penduduk di Kuala Lumpur dapat dilihat apabila proses pengeluaran susu dikawal dengan penuh peraturan. Seperkara yang perlu difahami di sini, Jabatan Kesihatan memainkan peranan memantau dari semasa ke semasa untuk mengekang masalah susu campuran. Pemantauan pada peringkat awal lagi bertujuan memastikan pembekal-pembekal tidak mengambil kesempatan mencampurkan susu lembu untuk mengaut keuntungan. Tindakan berhati-hati ini bertujuan mengekang campuran susu yang tidak baik untuk kesihatan terutama kanak-kanak. ${ }^{16}$

Menyedari susu begitu signifikan untuk kesihatan penduduk pada ketika itu, kawalan dengan penuh peraturan dilaksanakan agar hanya petender yang layak memperoleh tender membekalkan susu di Kuala Lumpur. Dalam hal ini, tugas Sanitary Board Kuala Lumpur menapis pihak yang berminat untuk mendapatkan tender susu melalui sampel susu yang dihantar terlebih dahulu. Zacharias \& Co merupakan antara petender yang menghantar sebut harga untuk mendapatkan tender membekalkan susu di Kuala Lumpur. Dalam konteks ini, Zacharias \& Co menawarkan sebut harga susu tin berjenama Fussel's Green Butterfly Pure Cow's Milk pada harga \$7.50 untuk 48 tin. Manakala itu, jenama Fussel's White Butterfly Pure Cow's Milk, Condensed Milk, Unsweetened untuk 48 tin susu ditawarkan pada harga $\$ 8.75$. $^{17}$

Di samping itu, Ellis \& Co tidak melepaskan peluang memohon tender membekalkan susu di Kuala Lumpur. Walaupun sampel susu merupakan salah satu syarat pemberian tender di Kuala Lumpur namun pihak Ellis \& Co mengambil keputusan tidak membekalkan sampel susu kepada State Surgeon. Pihak Ellis \& Co bertindak tidak membekalkan sampel susu kerana susu keluaran syarikat mereka telah ada di hospital. Oleh sebab itu, pihak hospital boleh mengambil secara rawak stok susu keluaran syarikat mereka untuk dijadikan sampel. Pihak Ellis \& Co berjanji untuk bertanggungjawab sepenuhnya menggantikan susu yang didapati rosak ketika dibuka untuk mendapatkan sampel. ${ }^{18}$ Berdasarkan sampel susu hanya pihak yang memenuhi kriteria mampu membekalkan susu berkualiti diberikan tender memasarkan susu di Kuala Lumpur. Prosedur pemberian sampel susu penting kerana banyak tender membekalkan susu segar untuk ke pusat perubatan seperti ke Institut Perubatan di Kuala Lumpur. ${ }^{19}$ Kawalan ketat 
bermula dari pemberian tender membuktikan kegiatan perniagaan susu begitu penting di Kuala Lumpur.

Syarat lain sebelum pemberian tender membekalkan susu di Kuala Lumpur ialah semakan harga susu setiap enam bulan. Idea ini dikemukakan oleh Jabatan Kesihatan untuk mengelakkan timbul sebarang permasalahan pada masa depan. Keadaan ini didorong kerana kegiatan perniagaan susu semakin kompetetif di Kuala Lumpur dan pembekal-pembekal susu berusaha menarik pembeli-pembeli dengan menurunkan harga pasaran masing-masing. Syarat ini dapat menjamin pembeli-pembeli susu mendapat bekalan susu dengan harga lebih murah di pasaran dan pada masa yang sama mengekalkan kualiti susu. ${ }^{20}$ Kedudukan sebegini hanya petender-petender yang menawarkan sebut harga menarik dan susu berkualiti ditawarkan tender membekalkan susu di Kuala Lumpur.

Tegasnya, perniagaan susu di Kuala Lumpur pada masa itu telah bergerak ke hadapan dan tidak menggunakan kaedah primitif semasa proses pembungkusan. Buktinya, penggunaan Alpha Filter No. 3 dan Extra Filter Medium dapat membantu proses menyaring susu dengan lebih baik. Manakala itu, penggunaan Hot Water Mixer dapat memastikan susu dikacau dalam kuantiti yang banyak dan sekata. ${ }^{21}$ Usaha memaksimumkan kualiti susu dapat dilihat dengan pengenalan berus khusus. ${ }^{22}$ Walaupun teknologi ini dianggap mudah pada saat ini, namun teknologi peralatan ini dikira penemuan baharu yang menjadikan proses pembekalan susu cekap saat itu. Keadaan ini secara tidak langsung mengesahkan kepentingan kegiatan perniagaan susu apabila peralatan inovasi ini diimport ke Kuala Lumpur melalui Crown Agents. ${ }^{23}$

Penggunaan mesin berteknologi membolehkan urusan membekalkan susu menjadi lebih efesien di Kuala Lumpur. Tugas memasukkan susu ke dalam botol menjadi lebih cekap apabila inovasi mesin berteknologi tinggi telah digunakan oleh pengusaha-pengusaha kegiatan perniagaan susu di Kuala Lumpur. 'Card board disc' berfungsi membantu proses menyukat susu ke dalam botol dan tin mengikut berat yang ditentukan lebih awal. Ini bermakna, 'Card board disc' berhenti dengan sendiri apabila sukatan susu telah cukup. ${ }^{24}$ Penggunaan 'Card board disc' dapat meningkatkan keberkesanan ketika proses menentukan sukatan susu tepat. Pada masa yang sama, penggunaan 'Card board disc' menjimatkan kerana dapat mengelakkan susu tertumpah ketika proses mengisi susu ke dalam botol.

Pada dasarnya botol atau tin yang digunakan untuk mengisi susu dapat menjamin susu yang dibekalkan di pasaran Kuala Lumpur bermutu tinggi. Memandangkan sifat susu yang mudah tercemar, prosedur membersihkan botol dan tin penting sebelum diisi susu. Oleh itu, jenis dan saiz berus perlu diberikan perhatian untuk menjamin kebersihan botol dan tin. Untuk memastikan tahap kebersihan botol dan tin susu, jenis berus yang digunakan perlu mengikut spesifikasi yang telah ditetapkan. Kebiasaannya berus untuk botol bernombor 17 dan berus tin pula bernombor 1. ${ }^{25}$ Dengan penggunaan berus yang sesuai dapat menjamin susu yang dibekalkan di pasaran Kuala Lumpur bermutu tinggi.

Proses memerah susu merupakan tahap awal untuk menjaga kebersihan susu sebelum dipasarkan kepada pembeli-pembeli. Hal ini berkaitan tahap kebersihan susu selepas proses memerah susu sebelum dimasukkan ke dalam botol mahupun tin. Untuk mengelakkan susu daripada tercemar bekas tin dan botol terus ditutup sebaik sahaja dimasukkan susu. Kesedaran kebersihan ini dapat memastikan susu yang dibekalkan di Kuala Lumpur berkualiti tinggi. Namun begitu untuk mengekalkan ketulenan susu penutup susu digunakan tidak mudah dibuka. Prosedur ini secara tidak langsung dapat menangani masalah campuran susu yang tidak baik untuk kesihatan. ${ }^{26}$ 
Urusan perlabelan produk susu di Kuala Lumpur diberikan keutamaan oleh pembekalpembekal susu dalam usaha untuk menguasai pasaran susu di Kuala Lumpur sekali gus dapat menarik perhatian pembeli. Prinsip memberi perhatian terhadap perlabelan tidak boleh dititik beratkan kerana merupakan salah satu strategi dalam pemasaran susu. Kebiasaannya pembeli melihat label terlebih dahulu sebelum membuat keputusan membeli susu. Perlabelan yang menarik dapat menyentuh hati pembeli-pembeli sekali gus membantu meningkatkan jualan susu. Kegiatan perniagaan susu diusahakan secara komersial memberi keutamaan dalam urusan perlabelan seperti melabelkan "K. L. Dairy" dapat dilihat di botol susu yang dipasarkan di Kuala Lumpur. ${ }^{27}$ Susu yang tertera label "K. L. Dairy" dapat menarik perhatian pembeli kerana proses pengeluaran susu dikawal dengan penuh peraturan dan proses pemasaran susu yang dikawal ketat. Secara tidak langsung, membuktikan susu yang dibekalkan dari Kuala Lumpur bermutu tinggi di pasaran. Maka strategi pemasaran menggunakan pelekat label ini penting untuk menarik minat pembeli-pembeli susu.

Penglibatan kerajaan British secara tidak langsung dalam kegiatan perniagaan susu dapat menjamin kualiti susu yang berada di pasaran di Kuala Lumpur. Perkara penting yang diberi perhatian oleh kerajaan British hanya membenarkan pembekal-pembekal yang layak menjual susu di Kuala Lumpur. Bagaimanapun pembekal-pembekal susu tertakluk kepada satu garis panduan memasarkan susu. Tujuan utama satu garis panduan diperkenalkan di Kuala Lumpur untuk mengawal cara pembekal-pembekal memasarkan susu di Kuala Lumpur. Hanya pembekalpembekal susu yang memiliki lesen dibenarkan membekalkan susu. Sebanyak 56 lesen telah dikeluarkan untuk penjualan susu di Kuala Lumpur. Dengan pemberian lesen mempercepat urusan pembekalan susu kepada pembeli-pembeli di Kuala Lumpur. ${ }^{28}$ Walau bagaimanapun pembekal susu perlu memperbaharui lesen sebelum dapat terus menjual susu di sekitar bandar Kuala Lumpur. Untuk mendapat memperbaharui lesen penjual susu perlu menunjukkan sijil terlebih dahulu. Langkah ini dapat membuktikan hanya peniaga-peniaga susu yang layak sahaja diberikan lesen. $^{29}$

Garis panduan mengenai susu yang dilaksanakan di Kuala Lumpur, dapat dikatakan tidak bersikap pilih kasih. Dalam erti kata lain, peniaga-peniaga susu, pembekal-pembekal susu dan syarikat gergasi masih tertakluk dengan garis panduan yang sama. Bagi membuktikan sikap tidak pilih kasih ini syarikat besar seperti Cold Storage Company di Kuala Lumpur telah dilaporkan oleh pegawai perubatan kerana mengimport susu tepung skim melalui Negeri-negeri Melayu Bersekutu (NNMB) tanpa lesen. Laporan dibuat berdasarkan Customs Enactment: Gazette Notification 2207 bertarikh 30 April 1926. ${ }^{30}$ Kawalan ketat ini menggambarkan kerajaan negeri mementingkan perniagaan susu di Kuala Lumpur.

Kegiatan perniagaan susu dikawal dengan ketat di Kuala Lumpur. Dengan penguatkuasaan undang-undang tegas berkaitan lesen penjualan susu hanya peniaga-peniaga yang sah dibenarkan menjual susu. Tanpa lesen yang sah peniaga-peniaga tidak dibenarkan menjual susu. Kegagalan mematuhi undang-undang ini menyebabkan peniaga-peniaga susu diambil tindakan. Berdasarkan undang-undang lesen penjualan susu ini, dua pembekal susu telah didakwa kerana menjual susu tanpa lesen dan dikenakan penalti sebanyak $\$ 30 .{ }^{31}$ Undang-undang tegas berkaitan susu membenarkan pembekal-pembekal susu yang melakukan kesalahan mencampur susu diambil tindakan. Penguatkuasaan undang-undang ini telah mendakwa sebanyak 19 orang pembekal kerana menjual susu yang telah dicampur dengan bahan kurang bermutu. Keseluruhan penalti yang dikenakan berjumlah $\$ 685$ untuk semua sabit kesalahan berkaitan susu yang disahkan dicampur bahan tidak berkualiti. ${ }^{32}$ Dengan penalti yang tinggi 
dapat memberi pengajaran kepada pembekal-pembekal susu agar lebih bertanggungjawab ketika memasarkan susu.

Pentadbiran Sanitary Board Kuala Lumpur telah bergerak secara proaktif dalam usaha mengesan peratusan campuran susu dan purata campuran dalam susu. Untuk mendapatkan bukti sainstifik dalam usaha mengesan campuran susu yang dijual di Kuala Lumpur sampel susu telah diambil untuk diuji ketulenan susu. Walaupun daripada segi praktiknya, konsep tersebut hanya angka. Namun hasil sampel susu tersebut dapat dijadikan bukti untuk diambil tindakan yang sewajarnya. Komitmen pentadbiran Sanitary Board Kuala Lumpur dapat dilihat apabila pada peringkat awal, beberapa sampel susu telah diambil secara rawak. Misalnya, pada tahun 1914, pentadbiran Sanitary Board Kuala Lumpur telah mengambil sebanyak 173 sampel susu dan sebanyak 4 peratus dikesan mengandungi campuran dalam susu. ${ }^{33}$ Pada tahun 1919, sebanyak 243 sampel susu telah diambil secara rawak dihantar ke Institute of Medical Research untuk dianalisis. Ternyata hasil analisis menunjukkan sampel susu ini tidak baik untuk kesihatan kerana mengandungi unsur campuran. ${ }^{34}$ Keaslian susu tercemar apabila mengandungi bahan campuran. ${ }^{35}$ Jumlah sampel yang diambil secara rawak berubah setiap tahun kerana mengambil kira jumlah penduduk di Kuala Lumpur. ${ }^{36}$ Langkah ini dapat mengelakkan pembeli-pembeli susu di Kuala Lumpur membeli susu yang tidak berkualiti. Dengan penalti yang tinggi dan analisis sampel susu dimakmal dapat membuktikan susu dikawal di Kuala Lumpur, memberi pengajaran kepada pembekal-pembekal susu agar lebih bertanggungjawab ketika memasarkan susu.

\section{Jadual 1: Jumlah sampel, peratus dan purata campuran susu yang diambil semasa pentadbiran Sanitary Board Kuala Lumpur dari tahun 1914-1918}

\begin{tabular}{|c|c|c|c|}
\hline Tahun & Jumlah sampel & Peratus campuran & Purata campuran \\
\hline 1914 & 173 & 4.00 & 7.81 \\
\hline 1915 & 291 & 20.27 & 20.46 \\
\hline 1916 & 390 & 8.16 & 15.47 \\
\hline 1917 & 435 & 14.71 & 18.41 \\
\hline 1918 & 240 & 24.28 & 14.71 \\
\hline
\end{tabular}

Sumber: Annual Report Sanitary Board Kuala Lumpur 1914-1918.

Satu notis arahan mengenai garis panduan mengenai susu telah dikeluarkan kepada penjual susu di Kuala Lumpur. Kandungan penting dalam notis arahan ini menghalang peniagapeniaga mengambil kesempatan menjual susu melebihi harga yang telah ditetapkan. Untuk memastikan maklumat yang terkandung dalam notis arahan difahami oleh penjual-penjual susu di Kuala Lumpur, notis arahan telah dicetak dalam beberapa bahasa seperti Bahasa Inggeris, Bahasa Melayu, Bahasa Tamil dan Bahasa Cina. Kegagalan peniaga-peniaga susu di Kuala Lumpur mematuhi notis arahan menyebabkan barangan perniagaan mereka dirampas. ${ }^{37}$ Sehubungan itu, untuk mengelak risiko kerugian barangan dirampas, peniaga-peniaga susu perlu mematuhi notis arahan tersebut. Terdapat dua justifikasi, notis arahan dicetak dalam empat bahasa. Pertama, menggambarkan penghuni Kuala Lumpur terdiri daripada empat kelompok masyarakat utama iaitu Melayu, Cina, India dan Eropah. Kedua, empat bahasa komunikasi digunakan di Kuala Lumpur ketika itu. 
Gambar 1: Notis arahan penetapan harga susu yang dicetak dalam empat Bahasa

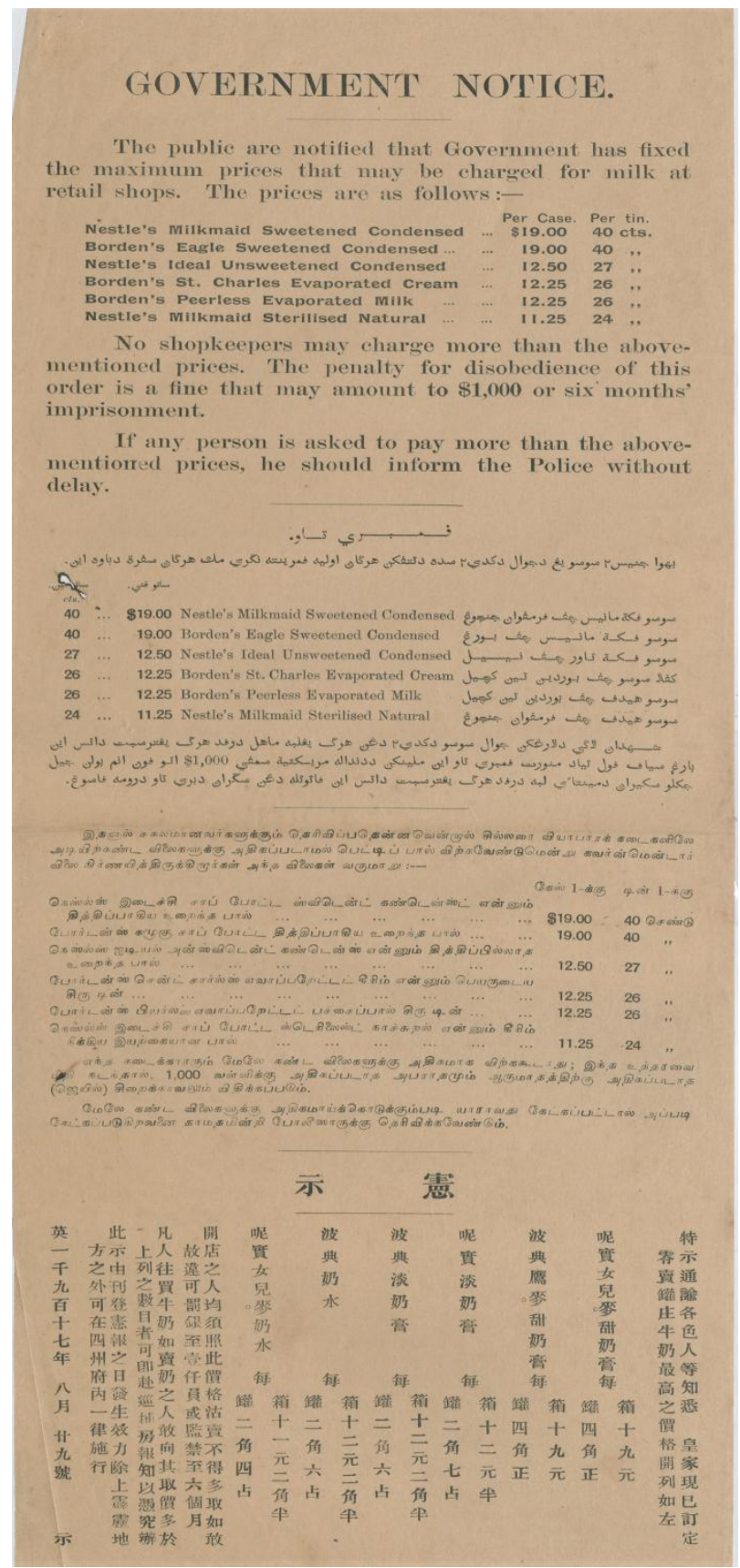

Sumber: Notice prohibiting the sale of milk beyond a certain price, dalam Fail Setiausaha Kerajaan Negeri Selangor, 13 Sept. 1917, Selangor 3770/1917, hlm. 3.

Ihsan daripada Arkib Negara Malaysia: No. Penerimaan 1957/0196462. 
Dalam notis arahan meliputi harga susu yang ditetapkan di Kuala Lumpur berbeza mengikut jenama. Susu berjenama Nestle's Milkmaid Sweetened Condensed dan Borden's Eagle Sweetened Condensed dijual dengan harga 40 sen setin, susu berjenama Nestle's Ideal Unsweetened Condensed dijual dengan harga 27 sen, Borden's St. Charles Evaporated Cream dijual dengan harga 26 sen, Borden's Peerless Evaporated Milk dijual dengan harga 26 sen dan Nestle's Milkmaid Sterilised Natural dijual dengan harga 24 sen. $^{38}$ Ini bermakna, peniagapeniaga perlu menjual susu jenama yang telah ditetapkan selaras notis arahan. Kegagalan peniaga-peniaga susu mematuhi arahan bakal berdepan tindakan tegas. Dalam konteks ini, peniaga-peniaga perlu akur dan tidak boleh sewenang-wenangnya menentukan harga pasaran susu. Pada masa yang sama penetapan harga susu dapat menjaga hak pembeli-pembeli susu daripada ditipu oleh peniaga-peniaga susu yang tidak bertanggungjawab di Kuala Lumpur.

Pembelian susu secara pukal lebih menguntungkan berbanding membeli setin susu. ${ }^{39}$ Harga pasaran susu berjenama Nestle's Milkmaid dapat dibeli secara pukal dengan harga \$20.50. Manakala susu berjenama Ideal Milk berharga \$13.30 di pasaran. Susu berjenama Milkmaid dan Borden's Peerless pula ditawarkan dengan harga yang paling murah di pasaran apabila boleh dibeli secara pukal dengan harga hanya $\$ 11.90 .{ }^{40}$ Peniaga-peniaga susu dapat merancang lebih awal menyediakan modal sebelum membeli stok susu. Perancangan awal membolehkan peniagapeniaga susu menjangka keuntungan jangka panjang. Penetapan harga beberapa jenama susu di Kuala Lumpur oleh ahli jawatankuasa kawalan harga diteruskan di Kuala Lumpur untuk melindungi hak penduduk agar penjual susu tidak menaikkan harga sewenang-wenangnya. ${ }^{41}$

Peniaga-peniaga susu di Kuala Lumpur bakal berdepan hukuman yang berat apabila gagal mematuhi arahan penetapan harga susu oleh kerajaan. Hal ini dapat dibuktikan apabila penalti sebanyak $\$ 1,000$ dikenakan kepada peniaga yang didapati bersalah. Di samping penalti, peniaga yang dikesan menaikkan harga susu dikenakan hukuman penjara selama enam bulan. ${ }^{42}$ Pada masa yang sama penduduk di Kuala Lumpur berhak melaporkan peniaga-peniaga susu yang gagal mematuhi arahan penetapan harga susu. Prosedur yang ditetapkan juga mudah, penduduk hanya melaporkan kepada pihak polis di Kuala Lumpur dengan kadar segera. Tindakan seterusnya diambil oleh pihak polis untuk melindungi hak-hak pembeli daripada dimanipulasi harga oleh peniaga-peniaga susu di Kuala Lumpur. ${ }^{43}$ Dalam erti kata lain pembelipembeli mempunyai kebebasan melaporkan sebarang bentuk salah laku yang dilakukan oleh peniaga-peniaga susu di Kuala Lumpur.

Setiap aduan yang diterima berkenaan bekalan susu di Kuala Lumpur dipandang serius. Kebebasan dalam membuat aduan secara tidak langsung telah memberi kuasa mutlak kepada pembeli-pembeli susu. Misalnya, aduan mengenai salah satu botol susu telah terbuka dan tidak berlabel bekalan susu ke Hospital Kuala Lumpur. ${ }^{44}$ Tindakan drastik telah diambil untuk menjamin kualiti susu kepada pesakit-pesakit yang dirawat di hospital. Rentetan itu, botol susu tersebut telah dihantar untuk dianalisis untuk mengetahui kandungan dalam susu. Hasil analisis menunjukkan contoh susu yang diambil mematuhi piawaian dalam Peraturan Kedua dalam "The Sale of Food \& Drugs Enactment 1913". " 45 Laporan turut dibuat terhadap kontraktor Iyasammy yang diberi tanggungjawab membekalkan susu ke General Hospital telah menggantikan susu lembu dengan susu kerbau. ${ }^{46}$ Pendedahan laporan secara terbuka dapat menjamin kualiti susu yang berada di pasaran Kuala Lumpur.

Pada awal abad ke-20 saiz pasaran susu di Kuala Lumpur semakin luas. Hal ini bersangkutan faktor permintaan domestik bekalan susu. Paling menarik bekalan susu di Kuala Lumpur tidak hanya dibekalkan ke hospital, tetapi juga dihantar ke penjara di Kuala Lumpur. Dalam konteks membekalkan susu kerajaan British tidak bertolak-ansur kerana menyedari 
kepentingan susu untuk kesihatan. Mengambilkira hal ini maka tidak hairanlah susu juga dibekalkan kepada banduan-banduan di Kuala Lumpur dengan peruntukan sebanyak \$1200.00. Peruntukan sebanyak $\$ 1200.00$ digunakan untuk pembayaran bekalan susu ke penjara di Kuala Lumpur dijelaskan oleh Jabatan Kesihatan. ${ }^{47}$ Situasi ini memberi satu gambaran bahawa pihak British tidak berkompromi dalam aspek kesihatan. Pasaran domestik susu yang luas menyebabkan kegiatan perniagaan susu lebih kompetetif di Kuala Lumpur. Pelbagai pendekatan digunakan oleh pembekal-pembekal susu untuk memasarkan susu keluaran mereka.

Pendekatan membawa masuk bekalan susu import ke Kuala Lumpur dari syarikat gergasi dalam industri susu iaitu Syarikat Nestle \& Anglo Swiss Condensed Milk Co. di London merupakan salah satu cara menggerakkan lagi perniagaan susu di Kuala Lumpur. Terdapat satu insiden kekeliruan dari segi jenama susu yang dijual di Kuala Lumpur melibatkan susu keluaran Syarikat Nestle \& Anglo Swiss Condensed Milk Co. di London Pihak Syarikat Nestle \& Anglo Swiss Condensed Milk Co. di London telah memaklumkan masalah ini berkemungkinan besar timbul kerana jenama susu yang mempunyai nama hampir sama. Pihak syarikat menegaskan tiada susu berjenama Ideal Milk Sterilised keluaran syarikat mereka. Pihak syarikat beranggapan jenama sebenar yang dimaksudkan Ideal Unsweetened Condensed. Pada sisi yang berbeza pihak syarikat bimbang kesalahan jenama susu bermula ketika pengisytiharan awal oleh pegawai kastam yang bertanggungjawab menguruskan bahagian perdagangan. Pihak syarikat menegaskan bahawa susu keluaran syarikat berjenama Unsweetened Condensed dan Milkmaid Sterilised Natural. Walau bagaimanapun pihak Syarikat Nestle \& Anglo Swiss Condensed Milk Co. di London meminta agar kerajaan memberi perhatian terhadap masalah ini dan melihat semula pemberitahuan dalam Government Gazette bertarikh 1 Mac $1918 .^{48}$ Langkah ini penting bagi merungkaikan permasalahan yang timbul ekoran jenama hampir sama.

\section{Kesimpulan}

Status Kuala Lumpur sebagai pusat pentadbiran British telah menjadikan bandar ini sebagai tumpuan pelbagai kegiatan ekonomi ketika itu. Berdasarkan bukti-bukti di atas, jelas memperlihatkan bahawa Kuala Lumpur merupakan platform terbaik untuk pasaran susu yang lebih luas. Bermula daripada proses pengeluaran hinggalah pemasaran susu dikawal ketat dengan penuh peraturan telah menjadi bukti jelas betapa signifikan perniagaan susu di Kuala Lumpur sebagai sumber pemakanan dan kesihatan. Walau bagaimanapun, kawalan ketat tidak menghalang rangkaian perniagaan susu menjadi salah satu kegiatan ekonomi yang begitu kompetetif di bandar Kuala Lumpur selain kegiatan perlombongan. Pelaksanaan notis arahan berkaitan garis panduan terperinci perniagaan susu dapat memastikan susu yang berada di pasaran Kuala Lumpur berkualiti. Keadaan ini membuktikan kerajaan negeri benar-benar mementingkan kegiatan ekonomi ini di Kuala Lumpur.

\section{Nota}

${ }^{1}$ Ekonomi dalam artikel ini merujuk gelagat atau perlakuan manusia dalam memperuntukkan sumber yang terhad untuk memenuhi kehendak dan keperluan dan kehendak yang terhad, yang bersaing antara satu sama lain. Mengikut P. A. Samuelson, ekonomi merupakan satu kajian tentang bagaimana individu atau masyarakat memilih, sama ada dengan menggunakan wang atau tidak, untuk menggunakan sumber yang produktif yang terhad, yang mungkin mempunyai alternatif penggunaan, mengagihkan komoditi itu; kegiatan manusia dalam pengeluaran, pengagihan 
dan penggunaan barang atau perkhidmatan. Untuk maklumat lanjut, rujuk Kamus Ekonomi, Kuala Lumpur: Penerbit Dewan Bahasa dan Pustaka, 1993, hlm. 31.

${ }^{2}$ Dari segi sejarah Raja Abdullah meneroka Kuala Lumpur. Raja Abdullah telah meminjam sebanyak \$30,000 daripada pedagang Cina di Melaka dan mengupah sebanyak 87 buruh Cina dari Lukut ke Ulu Sungai Klang untuk membuka meneroka kawasan perlombongan bijih timah yang baru awal di Kuala Lumpur. Untuk maklumat lanjut, rujuk J. M. Gullick, Kuala Lumpur 1880-1895 A City in The Making, Selangor: Penerbit Pelanduk Publications (M) Sdn. Bhd, 1988, hlm. 10; dari segi geografi Kuala Lumpur terletak lebih kurang 320 km dari garisan lintang Khatulistiwa iaitu antara garis lintang 3 darjah 0. 5 minit dan 3 darjah 11 minit utara. Lihat, Ahmad Kamal Ariffin Mohd Rus, Sanitary Board Kuala Lumpur: Peranan dan Pentadbirannya, 1890-1914, Kuala Lumpur: Penerbit Persatuan Sejarah Malaysia, 2001, hlm. 26.

${ }^{3}$ Kegiatan ditakrifkan sebagai aktiviti. Untuk maklumat lanjut, rujuk Kamus Dewan Edisi Keempat, Kuala Lumpur: Penerbit Dewan Bahasa dan Pustaka, 2007, hlm. 471.

${ }^{4}$ Dalam artikel ini susu merujuk kepada susu segar daripada haiwan ternakan seperti lembu dan kerbau, susu kental, susu cair dan susu tepung yang telah diproses. Susu kental mahupun susu tepung merupakan susu yang telah diproses menggunakan kaedah pengewapan dengan tekanan atau suhu tinggi. Untuk maklumat lanjut, rujuk Kamus Dewan Edisi Keempat, Kuala Lumpur: Penerbit Dewan Bahasa dan Pustaka, 2007, hlm. 1552-1553.

${ }^{5}$ Shapiza Sharif, Arba'iyah Mohd Noor, Kegiatan Perniagaan Susu di Kuala Lumpur Pada Awal Abad ke-20, dalam Sivachandralin Sundara Raja, Arba'iyah Mohd Noor et.al., Prosiding Persidangan Sejarah Sosioekonomi Malaysia, Universiti Malaya, 23-24 November 2016, hlm. 690.

${ }^{6}$ Annual Report for the year 1905, dalam Fail Setiausaha Kerajaan Negeri Selangor, 2 Okt. 1917, 1102/1906, hlm. 9.

${ }^{7}$ Application for contract to supply milk to Hospitals in Kuala Lumpur for 1919, dalam Fail Setiausaha Kerajaan Negeri Selangor, 2 Okt. 1917, Selangor 348/1918, hlm. 2.

${ }^{8}$ Manjit Singh Sindhu, Kuala Lumpur and Its Population, Kuala Lumpur: University of Malaya Press, 1978, hlm. 13.

${ }^{9}$ Dairy appliances-Indent on Crown Agents for: Indent No.14/23, dalam Fail Setiausaha Kerajaan Negeri Selangor, 16 Mac 1923, SEL:SEC: 1895/1923, hlm. 9.

${ }^{10}$ Ibid.

${ }^{11}$ Ibid.

${ }^{12}$ Notice prohibiting the sale of milk beyond a certain price, dalam Fail Setiausaha Kerajaan Negeri Selangor, 13 Sept. 1917, Selangor 3770/1917, hlm. 3.

${ }^{13}$ Tenders for unsweetened canned milk, cow and buffalo milk, aerated waters, coffin's, washing hospital clothing, dalam Fail Setiausaha Kerajaan Negeri Selangor, 25 Oktober 1906, 6164/1906, hlm. 18.

${ }^{14}$ Notice prohibiting the sale of milk beyond a certain price, dalam Fail Setiausaha Kerajaan Negeri Selangor, 13 Sept. 1917, Selangor 3770/1917, hlm. 3.

15 Application for 25 acres of land in Kuala Lumpur for dairy and poultry forms, dalam Fail Setiausaha Kerajaan Negeri Selangor, 15 April 1919, Selangor 1862/1919, hlm. 2.

${ }^{16}$ Ibid.

${ }^{17}$ Tenders for unsweetened canned milk, cow and buffalo milk, aerated waters, coffin's, washing hospital clothing, dalam Fail Setiausaha Kerajaan Negeri Selangor, 25 Oktober 1906, 6164/1906, hlm. 18. Pada akhir abad ke -19, tender yang ditawarkan tertumpu dalam susu segar. Pada tahun 1898, petender yang yang berjaya mendapat kontrak membekalkan susu segar ke Hospital di Kuala Lumpur ialah Ram Singh, Puran Singh, Somasundram, Sam Ah Wing. Untuk maklumat lanjut, rujuk tenders for the supply of milk, during 1898 to Kuala Lumpur and District Hospitals, dalam Fail Setiausaha Kerajaan Negeri Selangor, 11 Oktober 1897, 4968/1897, hlm. 5-23.

${ }^{18}$ Supply of sterilized milk for 1908, dalam Fail Setiausaha Kerajaan Negeri Selangor, 5 Nov. 1907, 6004/1907, hlm. 7.

${ }^{19}$ Supply of fresh milk to Medical Institutions, Kuala Lumpur, Daily Kuala Lumpur, dalam Fail Setiausaha Kerajaan Negeri Selangor, 28 Feb. 1921, Sel. Sect. 1117/1921, hlm. 7.

${ }^{20}$ Municipal Dairy:Kuala Lumpur-Contract with vendor for the supply of milk to Hospital at Kuala Lumpur, dalam Fail Setiausaha Kerajaan Negeri Selangor, 6 Januari 1922, SEL:SEC: 4429/1922, hlm. 7.

${ }^{21}$ Dairy appliances-Indent on Crown Agents for: Indent No.14/23, dalam Fail Setiausaha Kerajaan Negeri Selangor, 16 Mac 1923, SEL:SEC: 1895/1923, hlm. 9.

${ }^{22}$ Ibid.

${ }^{23}$ Ibid. 
${ }^{24}$ Indent on Crown Agents for weighing machines for the Milking Sheds, dalam Fail Setiausaha Kerajaan Negeri Selangor, SECRETARIAT SELANGOR 2419/1913, 5 Mei 1914, hlm. 22.

${ }^{25}$ Dairy appliances-Indent on Crown Agents for: Indent No.14/23, dalam Fail Setiausaha Kerajaan Negeri Selangor, 16 Mac 1923, SEL:SEC: 1895/1923, hlm. 9.

${ }^{26}$ Indent on Crown Agents for weighing machines for the Milking Sheds, dalam Fail Setiausaha Kerajaan Negeri Selangor, SECRETARIAT SELANGOR 2419/1913, 5 Mei 1914, hlm. 22.

${ }^{27}$ Dairy appliances-Indent on Crown Agents for: Indent No.14/23, dalam Fail Setiausaha Kerajaan Negeri Selangor, 16 Mac 1923, SEL:SEC: 1895/1923, hlm. 9.

${ }^{28}$ Annual Report 1905, Sanitary Board Kuala Lumpur dalam Fail Setiausaha Kerajaan Negeri Selangor, 1102/1906, hlm. 9.

${ }^{29}$ Licensing of Milk Vendors within the Kuala Lumpur Town Board Area, dalam Fail Setiausaha Kerajaan Negeri Selangor, 24 Januari 1946, SEL. C. A. 76/1946, hlm. 7.

${ }^{30}$ Informs that the Cold Storage Company, Kuala Lumpur are importing skimmed milk powder into Federated Malay States without a licence, dalam Fail Setiausaha Kerajaan Negeri Selangor, 6 Mac 1937, Sel. Sec. General. 126/1937, hlm. 3 .

${ }^{31}$ Annual Report 1905, Sanitary Board Kuala Lumpur dalam Fail Setiausaha Kerajaan Negeri Selangor, 1102/1906, hlm. 9 .

${ }^{32}$ Ibid.

${ }^{33}$ Annual Report 1918 Sanitary Board Kuala Lumpur, dalam Fail Setiausaha Kerajaan Negeri Selangor, Selangor 1016/1919, hlm. 20.

${ }^{34}$ Ibid.

${ }^{35}$ Ahmad Kamal Ariffin Mohd Rus, 'Sanitary Board' Kuala Lumpur: Peranan dan Pentadbiran 1890-1914, Kuala Lumpur: Penerbit Persatuan Sejarah Malaysia, 2001, hlm. 121.

${ }^{36}$ Annual Report 1918 Sanitary Board Kuala Lumpur, dalam Fail Setiausaha Kerajaan Negeri Selangor, Selangor 1016/1919, hlm. 20.

${ }^{37}$ Notice prohibiting the sale of milk beyond a certain price, dalam Fail Setiausaha Kerajaan Negeri Selangor, 13 Sept. 1917, Selangor 3770/1917, hlm. 2.

${ }^{38}$ Ibid., hlm. 3. Pada peringkat awal hanya susu segar dijual, sebelum susu tin berada di pasaran Kuala Lumpur. Susu segar yang dibekalkan ke hospital-hospital berharga 13 sen 'per chupah'. Harga susu segar ini telah meningkat 2 sen menjadi 15 sen 'per chupah' pada tahun 1899. Bekalan susu segar dihantar ke hospital umum, hospital rawatan sakit kusta dan tempat rawatan orang yang mengalami masalah mental di Kuala Lumpur. Untuk maklumat lanjut, rujuk supply of fresh milk, General District, Leper Hospitals, Lunatic Asylum and Prison Kuala Lumpur 1899, dalam Fail Setiausaha Kerajaan Negeri Selangor, 14 Nov. 1898, 5339/1898, hlm. 3.

${ }^{39}$ Sale price of certain brands of Milk fixed by the Committee of Food Control, dalam Fail Setiausaha Kerajaan Negeri Selangor, 24 April 1918, SEL:2108/1918, hlm. 5.

${ }^{40}$ Ibid., hlm. 1.

${ }^{41}$ Ibid., hlm. 6.

${ }^{42}$ Notice prohibiting the sale of milk beyond a certain price, dalam Fail Setiausaha Kerajaan Negeri Selangor, 13 Sept. 1917, Selangor 3770/1917, hlm. 3.

${ }^{43}$ Ibid.

${ }^{44}$ Complaints against the milk supplied to Hospitals Kuala Lumpur., dalam Fail Setiausaha Kerajaan Negeri Selangor, 1 Nov. 1922, SEL. SECT. 4492/1922, hlm. 7.

${ }^{45}$ Ibid., hlm. 8.

${ }^{46}$ Report that the present contractor Iyasammy supplies to the General Hospital buffaloes milk and charges for cows' milk, dalam Fail Setiausaha Kerajaan Negeri Selangor, 25 November 1908, 5890/1908, hlm. 4-5.

${ }^{47}$ Vote "Medical Comforts \& Contingent-Expenses Gaol Hospital" - Asks that a milk diet be added to the Gaol Diet - List or for a Supplementary Vote of \$1200.00, dalam Fail Setiausaha Kerajaan Negeri Selangor, 11 April 1896, MEDICAL 2154/1896, hlm. 5-6.

${ }^{48}$ Sale price of certain brands of Milk fixed by the Committee of Food Control, dalam Fail Setiausaha Kerajaan Negeri Selangor, 24 April 1918, SEL:2108/1918, hlm. 24. 